-Supporting Information

\title{
Defect Engineering of Out-of-Plane Charge Transport in van der Waals Heterostructures for Bi-Direction Photoresponse
}

Yanran Liu ${ }^{\dagger}$, Yue Liu ${ }^{\dagger}$, Hua Zhout, Zaixing Yang ${ }^{\dagger}$, Yuanyuan $Q u^{*},+$ Yang Tan ${ }^{* \dagger}$ and Feng Chen ${ }^{* \dagger}$

'School of Physics, State Key Laboratory of Crystal Materials, Shandong University, Shandong, Jinan, 250100, P. R. China 
SEM Image of Partial Irradiated $\mathrm{MoSe}_{2}$

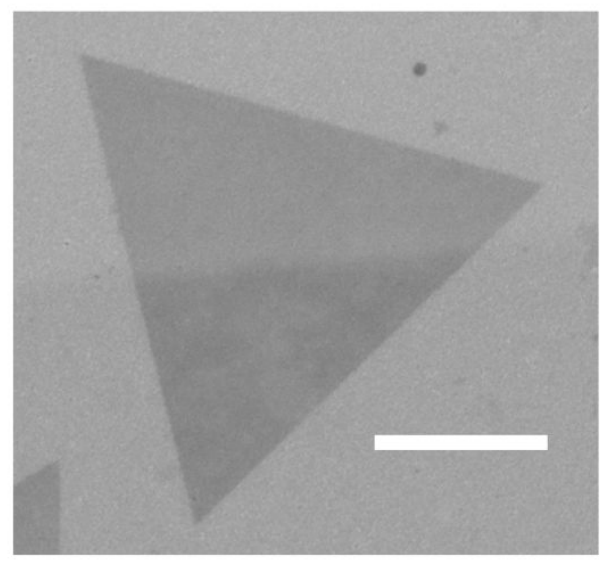

Figure S1 SEM image of partial irradiated $\mathrm{MoSe}_{2}$ in Fig. 2a, 2b, and 2c. The irradiated/non-irradiated region is above/below the dotted line. 
XPS Spectra of $\mathrm{MoSe}_{2-\mathrm{x}} /$ Graphene
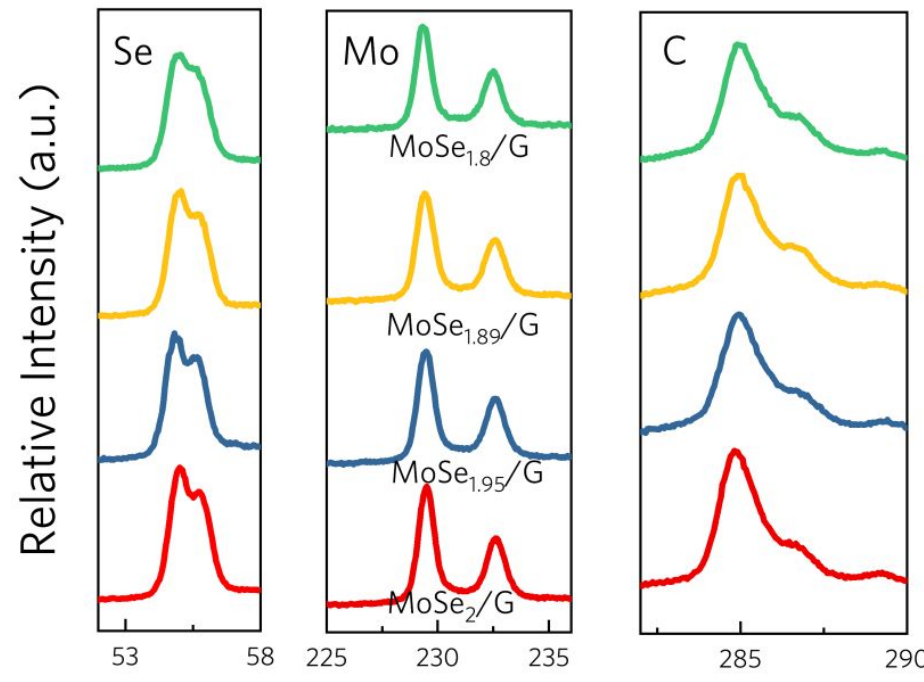

Binding Energy

Figure S2 XPS spectra of $\mathrm{MoSe}_{2.0} / \mathrm{G}, \mathrm{MoSe}_{1.95} / \mathrm{G}, \mathrm{MoSe}_{1.89} / \mathrm{G}$ and $\mathrm{MoSe}_{1.8} / \mathrm{G}$, respectively. 


\section{Calculation of Irradiation Ion Fluence}

The dose of irradiation is calculated by

$$
\mathrm{D}=\frac{I t_{d} N_{s}}{q A}
$$

where $t_{d}$ is the dwell time, $N_{s}$ is the number of scans, and $A$ is the exposure area of the ion beam, $I$ is the beam current. In this work, $t_{d}$ is $1 \mu \mathrm{s}, A$ is $2.7 \times 10^{3} \mu \mathrm{m}^{2}, I$ is $9.7 \mathrm{pA}, 93$ $\mathrm{pA}$, and $0.79 \mathrm{nA}$, respectively. 
The Variation of Dark Current for $\mathrm{MoSe}_{2-\mathrm{x}} /$ Graphene

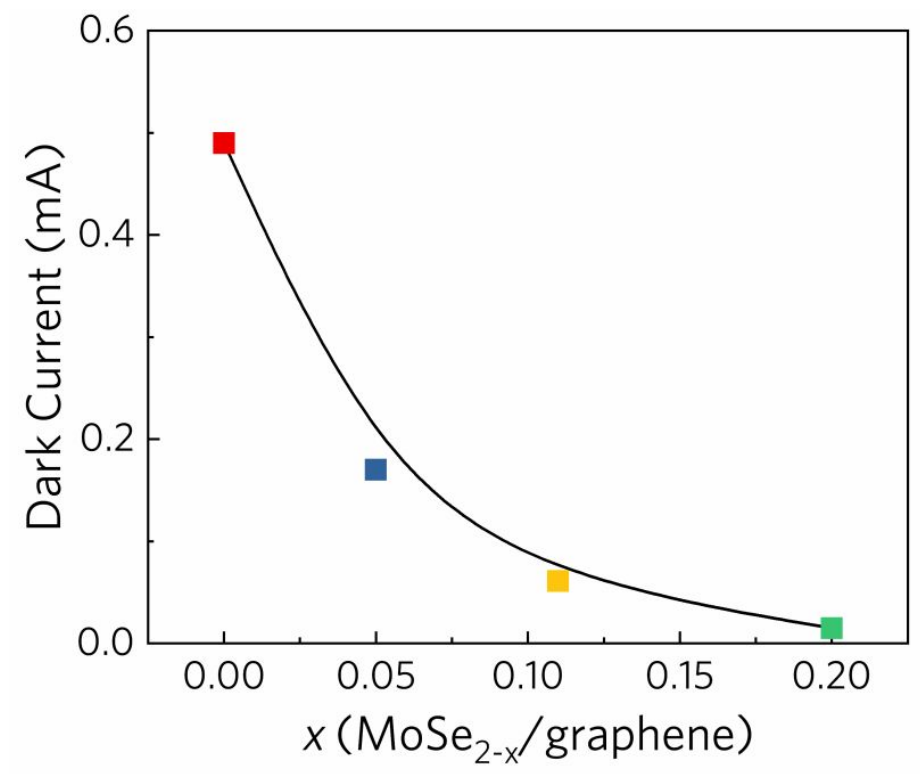

Figure S3 Dark current of $\mathrm{MoSe}_{2-\mathrm{x}} /$ graphene heterostructures of $x=0,0.05,0.11$, and 0.2 , respectively. The drain voltage is $0.5 \mathrm{~V}$. 
The Variation of Photocurrent for $\mathrm{MoSe}_{2-\mathrm{x}} / \mathrm{Graphene}$ with Different Drain

\section{Voltage}

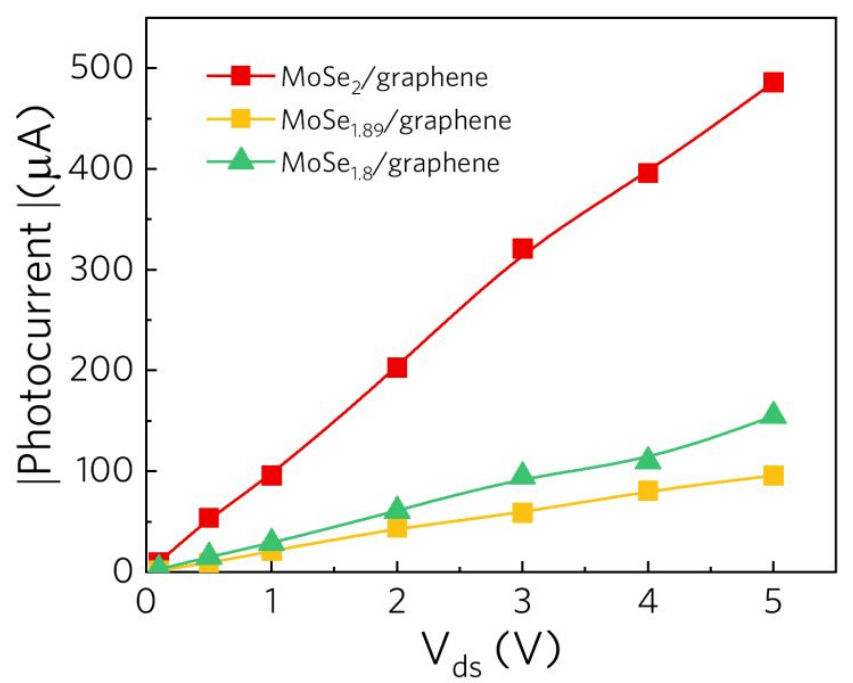

Figure S4 The absolute values of photocurrent of $\mathrm{MoSe}_{2} /$ graphene, $\mathrm{MoSe}_{1.89} /$ graphene and $\mathrm{MoSe}_{1.8} /$ graphene with different drain voltage. The light intensity of the probe laser is $3.54 \mathrm{~mW} / \mathrm{cm}^{2}$, and the wavelength is $632.8 \mathrm{~nm}$. 
Responsivity and Dectecivity $\left(\mathrm{D}^{*}\right)$ of $\mathrm{MoSe}_{1.89} / \mathrm{Graphene}$
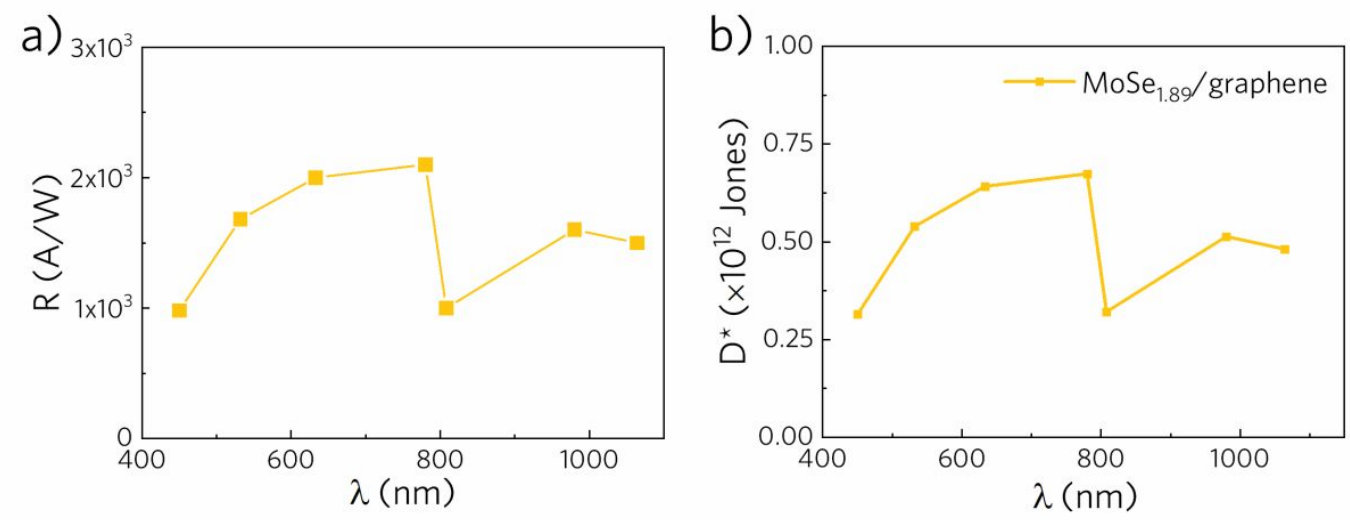

Figure S5 Responsivity (R) and dectecivity (D*) of $\mathrm{MoSe}_{1.89}$ /graphene heterostructure varying with the wavelength from $450 \mathrm{~nm}$ to $1064 \mathrm{~nm}$. 


\section{Optical Logic Gates for NIR}

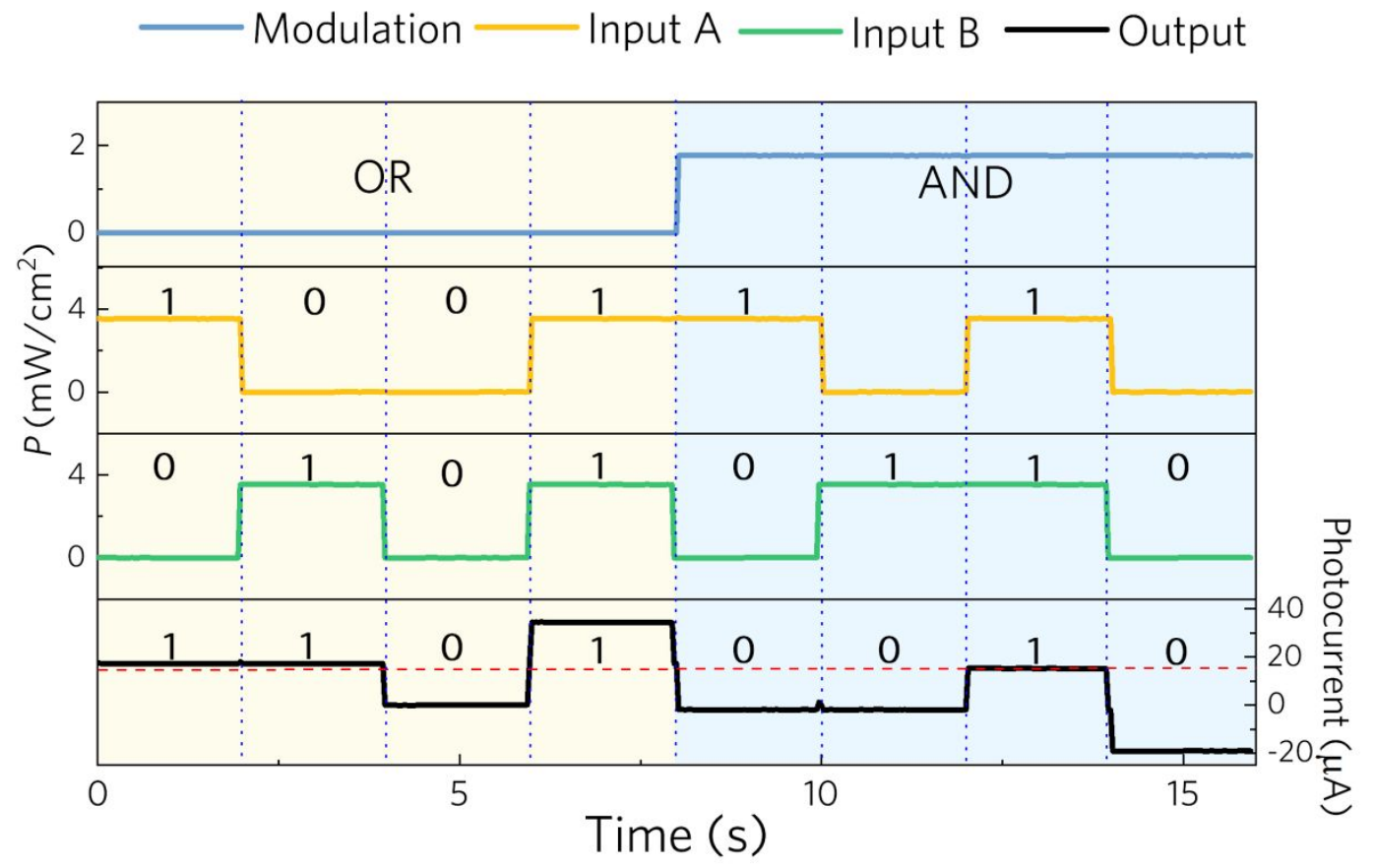

Figure S6 The response in output current versus time, corresponding to different input configurations of OR gate and AND gate. The wavelength of the operation light is 1064 $\mathrm{nm}$. The threshold photocurrent for output is $15 \mu \mathrm{A}$. And the drain voltage is $0.5 \mathrm{~V}$. 


\section{Energy Disperse Spectroscopy of $\mathrm{MoSe}_{2} / \mathrm{Graphene}$ and $\mathrm{MoSe}_{1.8} / \mathrm{Graphene}$}
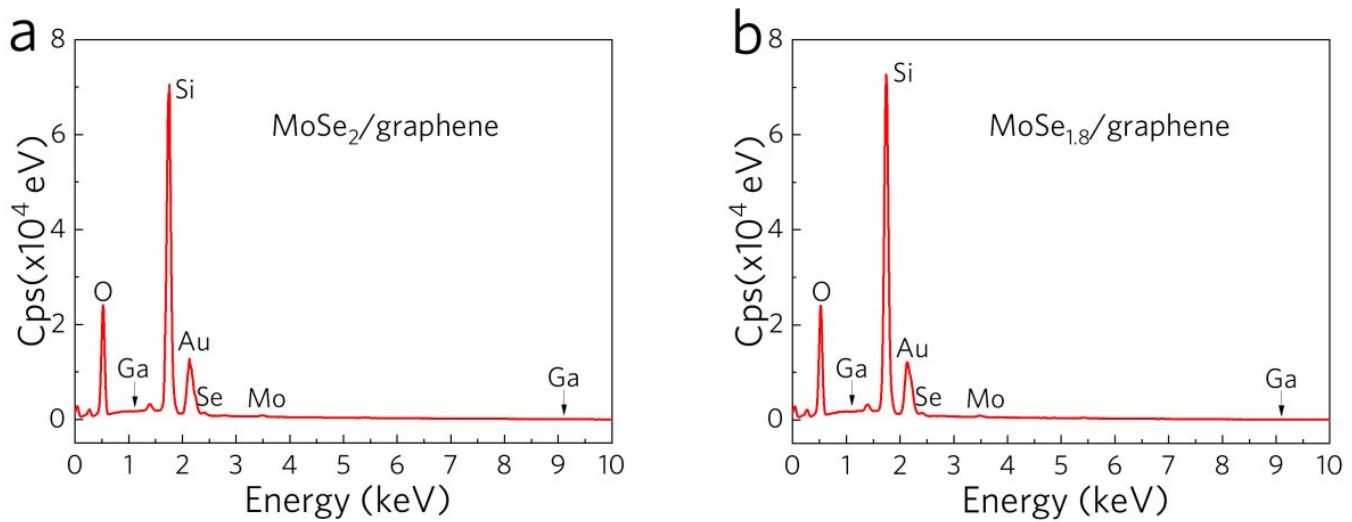

Figure S7 The Energy Disperse Spectroscopy (EDS) of (a) $\mathrm{MoSe}_{2} /$ graphene and (b)

$\mathrm{MoSe}_{1.8} /$ graphene. There is no Ga signal in the spectrum. 
High-Resolution XPS Spectrum of $\mathrm{MoSe}_{1.8} /$ Graphene

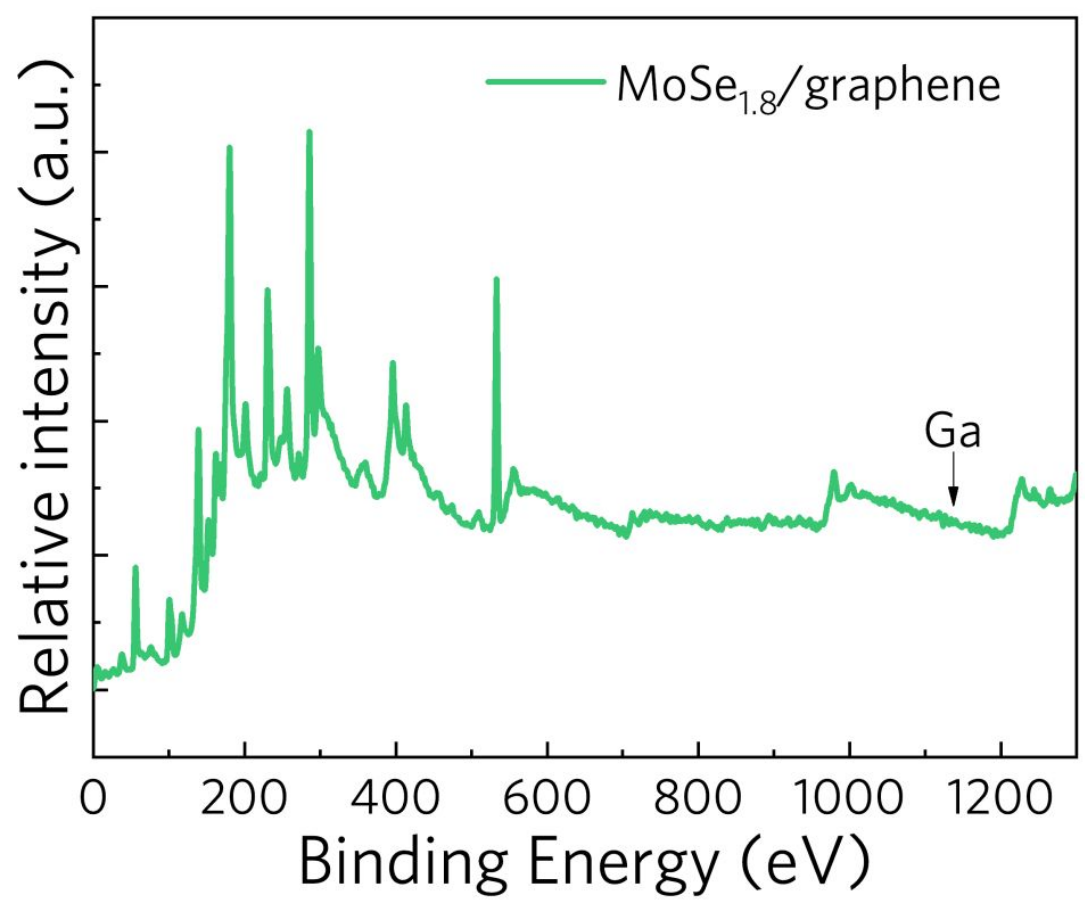

Figure S8 The high-resolution XPS spectrum of $\mathrm{MoSe}_{1.8} /$ graphene heterostructure. There is no peak of in the spectrum. 
PL Spectrum of $\mathrm{MoSe}_{2-\mathrm{x}} /$ Graphene

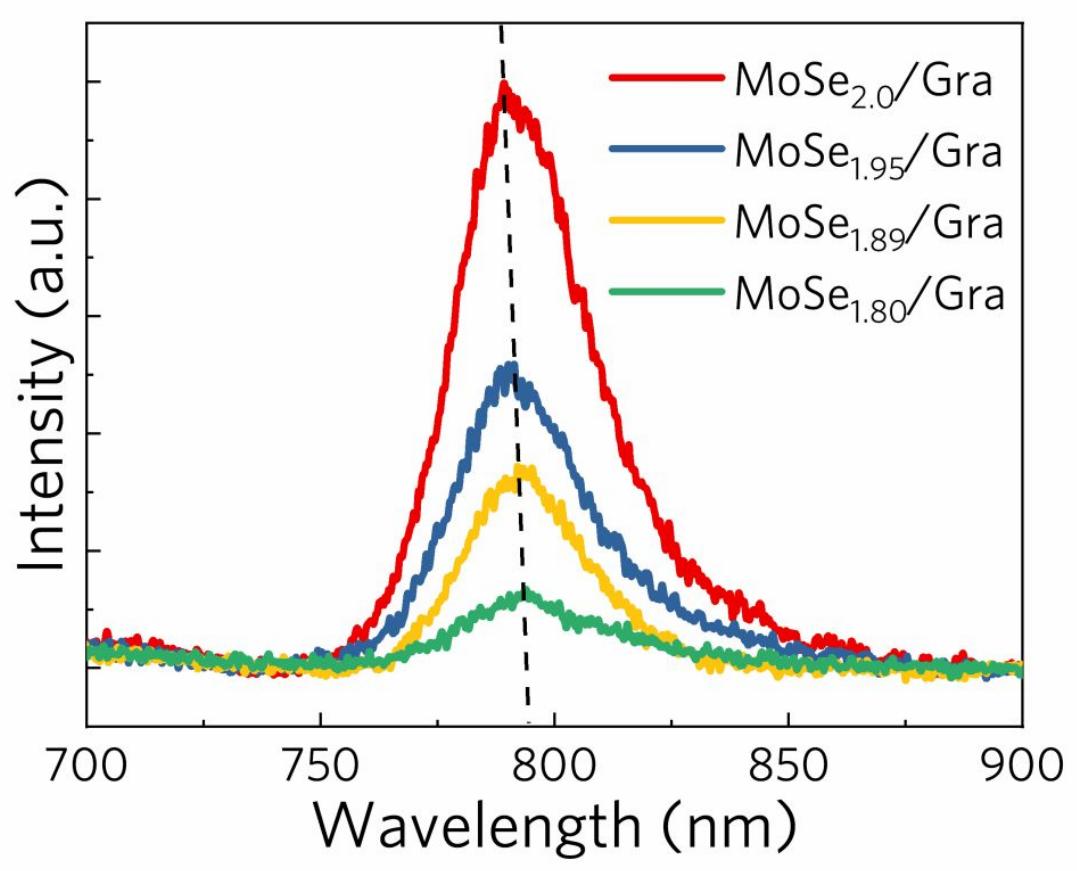

Figure S9 PL spectrum of $\mathrm{MoSe}_{2} /$ graphene, $\mathrm{MoSe}_{1.95} /$ graphene, $\mathrm{MoSe}_{1.89} /$ graphene and $\mathrm{MoSe}_{1.8} /$ graphene heterostructures, respectively. 


\section{Fs Optical Pump-Probe Spectroscopy}
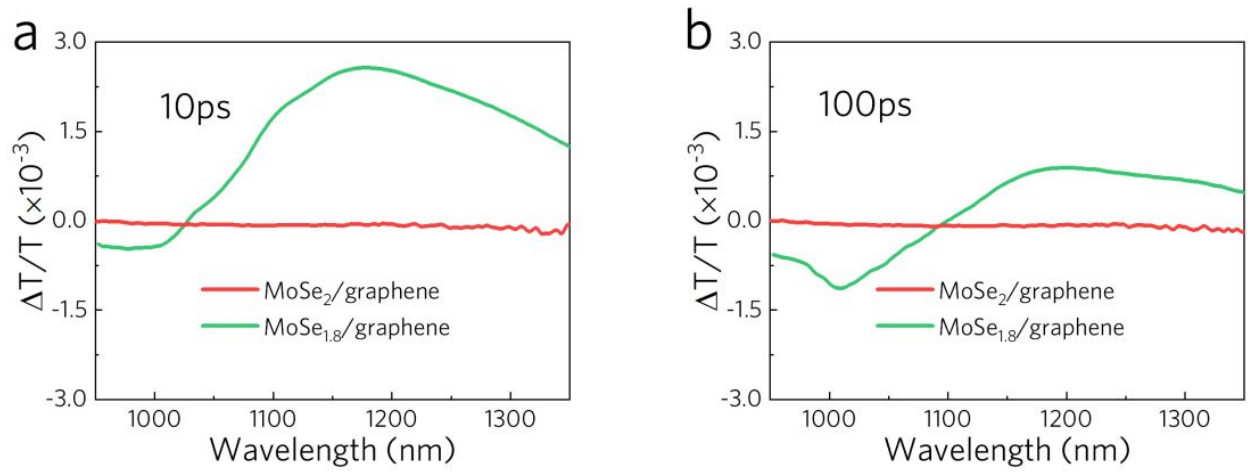

Figure S10 The intensity of fs optical pump-probe spectroscopy $\left(\Delta \mathrm{T} / \mathrm{T}_{0}\right)$ of $\mathrm{MoSe}_{2} /$ graphene and $\mathrm{MoSe}_{1.8} /$ graphene in the near infrared range at a time of (a) $10 \mathrm{ps}$ and (b) 100ps, respectively. 


\section{$\mathrm{I}_{\mathrm{DS}}-\mathrm{V}_{\mathrm{G}}$ of $\mathrm{MoSe}_{2-\mathrm{x}} / \mathrm{Graphene}$}
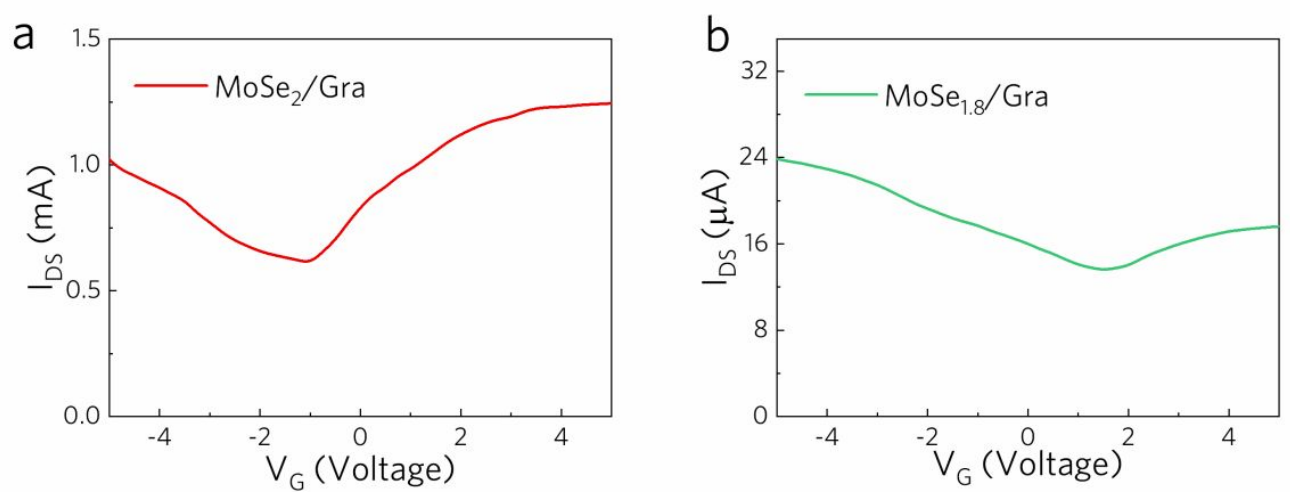

Figure $\mathrm{S} 11 \mathrm{I}_{\mathrm{DS}}-\mathrm{V}_{\mathrm{G}}$ of $\mathrm{MoSe}_{2} /$ graphene $(\mathbf{a})$ and $\mathrm{MoSe}_{1.8} /$ graphene $(\mathbf{b}) .\left(\mathrm{V}_{\mathrm{DS}}=0.5 \mathrm{~V}\right)$

We fabricated top-gated field-effect transistors (FETs) based on the $\mathrm{MoSe}_{1.8} /$ graphene and $\mathrm{MoSe}_{1.8} /$ graphene. The FETs exhibit the typical ambipolar transport behavior with the Dirac point shifted from the gate voltage of $-2.0 \mathrm{~V}(\mathrm{x}=0)$ to $1.5 \mathrm{~V}(\mathrm{x}=0.2)$. 
Time Stabilty of $\mathrm{MoSe}_{1.8} /$ Graphene

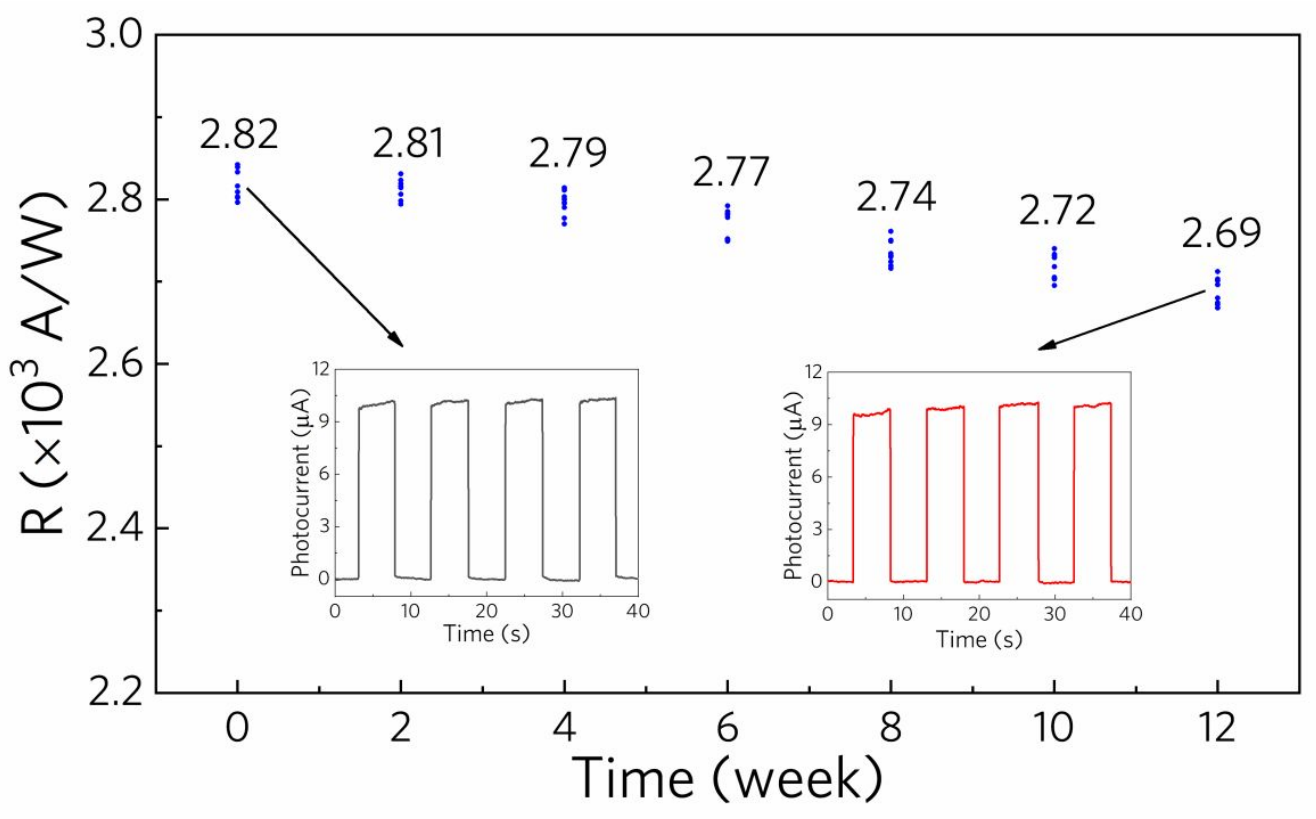

Figure S12 Photoresponsivity $(\mathrm{R})$ of the $\mathrm{MoSe}_{1.8} /$ graphene heterostructure within 12 weeks. The wavelength of the probe laser is $632.8 \mathrm{~nm}$, the drain voltage is $0.5 \mathrm{~V}$.

Insert is the time-resolved photoresponse of photodetector based on $\mathrm{MoSe}_{1.8} /$ graphene at week 0 and week 12, respectively. The samples are stored in room temperature, under the humidity of $20 \%$ and vacuum of $-60 \mathrm{kPa}$. 


\section{Repeatability of $\mathrm{MoSe}_{1.8} /$ Graphene}

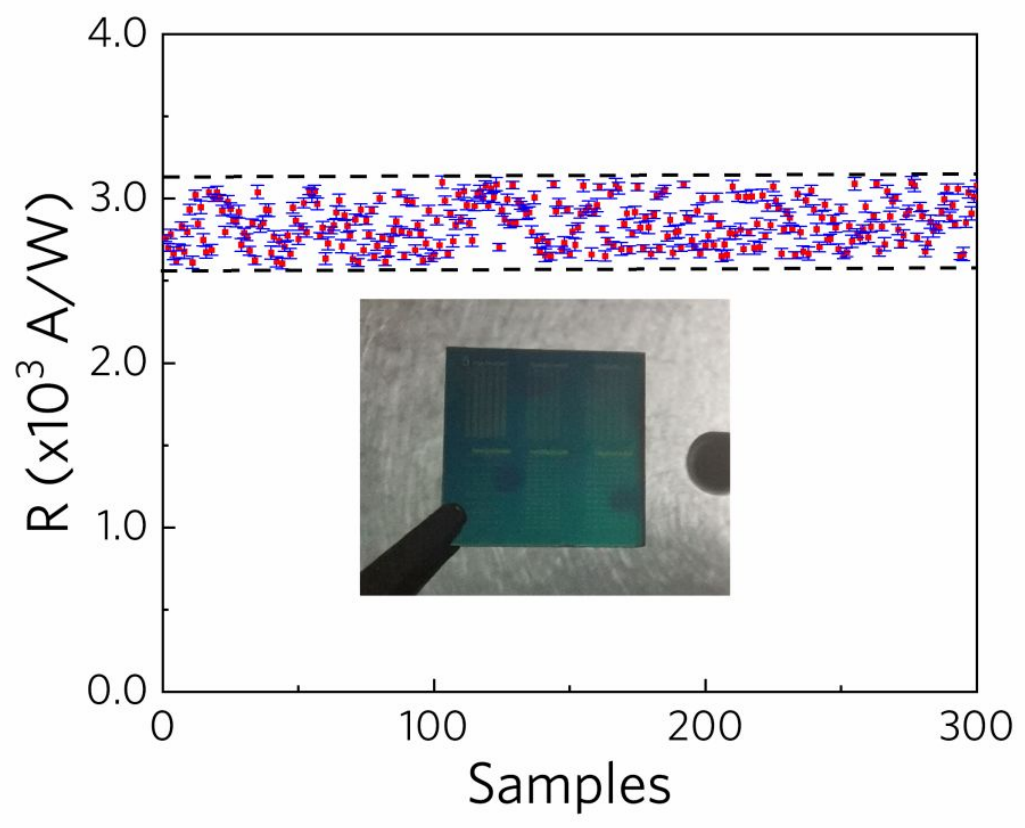

Figure S13 Photoresponsivity (R) of the $\mathrm{MoSe}_{1.8} /$ graphene heterostructure of 300 different samples. The wavelength of the probe laser is $632.8 \mathrm{~nm}$. The drain voltage is $0.5 \mathrm{~V}$.

We have measured more than 300 samples. As is shown in the picture, the differences of these samples is less than $10 \%$. That means the defect-engineer have good repeatability. 
Electronic Structure and DOS of $\mathrm{MoSe}_{2}$ and $\mathrm{MoSe}_{1.8}$ Monolayer
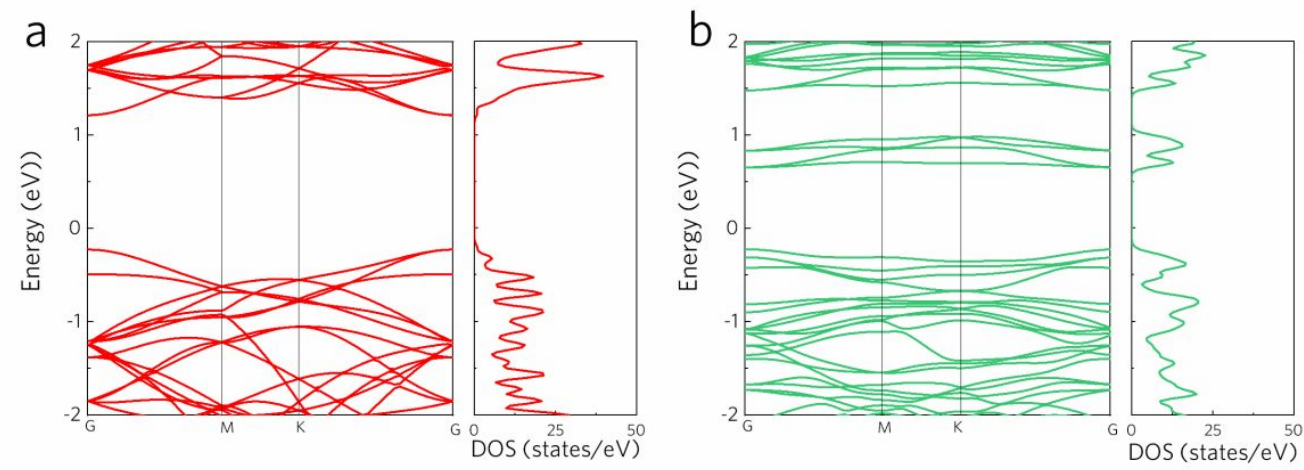

Figure S14 Electronic structure and DOS based on the first principle caculation of (a) $\mathrm{MoSe}_{2}$ and (b) $\mathrm{MoSe}_{1.8}$ monolayer. 